\title{
Mesures in vivo et in situ de l'activité nitrate réductase chez le pêcher (Prunus persica (L.) Batsch)
}

\author{
C. Bussi ${ }^{1}$, R. Habib ${ }^{2}$ et L. Salsac ${ }^{3}$, avec la collaboration technique de M. Cotte et F. Combe \\ 1 INRA - SRIV, domaine de Gotheron, 26300 Saint-Marcel-lès-Valence; \\ 2 INRA, Station d'agronomie, domaine Saint-Paul, Centre de recherches d'Avignon, 84140 Montfavet; \\ 3 ENSA - INRA, Laboratoire d'étude des symbiotes des racines, place Viala, 34060 Montpellier, France
}

(reçu le 6-7-1988, accepté le 26-1-1989)

\begin{abstract}
Résumé - Une activité nitrate réductase (ANR) est détectable chez le pêcher à l'aide des méthodes de mesure in vivo et in situ. La valeur de cette activité dépend des conditions d'incubation (durée, température, concentration en nitrate du milieu) et de prélèvement (type de feuille, heure de la journée). L'activité nitrate réductase foliaire est inductible par son substrat, le nitrate; l'ANR foliaire maximale obtenue après induction est de l'ordre de $2 \mu \mathrm{mol} . \mathrm{NO}_{2}{ }^{-} \cdot \mathrm{h}^{-1}$. $\mathrm{g}^{-1}$ MF. Une activité NR a pu aussi être décelée dans des racines de pêchers à l'aide des méthodes de mesure in vivo et in situ. Cette nitrate réductase s'avère également inductible par son substrat. Dans nos conditions d'expérience, l'activité de cette enzyme au niveau des racines apparaît supérieure à celle mesurée au niveau des feuilles.
\end{abstract}

incubation - induction - feuilles - racines - concentration en nitrate

Summary - Peach-tree (Prunus persica (L.) Batsch) in vivo and in situ nitrate reductase activity assays. $A$ nitrate reductase activity (NRA) in peach-tree leaves is detected using in vivo or in situ assays. This nitrate reductase activity is affected by conditions of incubation (duration, temperature, nitrate concentration of the medium) and of sample (type of leaf, hour of the day). Furthermore, the leaf nitrate reductase activity is induced by nitrate; the highest NRA obtained in leaves after induction is about $2 \mu \mathrm{mol} . \mathrm{NO}_{2}-h^{-1} \cdot g^{-1} \mathrm{FW}$. A root NRA has also been found with in situ and in vivo assays. This nitrate reductase is induced by nitrate, too. But the root NRA is more important than leaf NRA in our experimental conditions.

incubation - induction - leaves - roots - nitrate concentration

\section{Introduction}

De faibles teneurs en nitrate dans la sève du xylème et, inversement, la prédominance d'acides aminés ou d'uréides seraient l'indice d'une réduction du nitrate localisée dans les racines (Pate, 1973). Cette prépondérance des composés organiques de l'azote dans la sève du pommier (Malus sylvestris) a suggéré que la réduction du nitrate chez les rosacées fruitières s'effectuait exclusivement dans les racines (Bollard, 1957; Taylor et Van Den Ende, 1969; Habib, 1984).

Cependant, Klepper et Hageman (1969) constataient l'existence d'une activité nitrate réductase (ou activité NR ou ANR) dans les feuilles du pommier. Cette activité foliaire était mise en évidence chez d'autres rosacées fruitières: abricotier (Prunus armeniaca), cerisier (Prunus avium) et prunier (Prunus domestica), (Leece et al., 1972). La nitrate réductase étant une enzyme inductible par le nitrate, ces observations inspiraient l'idée qu'au moins une partie du $\mathrm{NO}_{3}$ absorbé était réduit dans les feuilles.

La localisation de la réduction du nitrate est donc mal connue chez les rosacées fruitières. Dans le cadre de ce travail, nous avons tenté de détecter une activité nitrate réductase et de préciser le lieu de réduction principal, soit dans les feuilles, soit dans les racines, chez l'espèce pêcher, pour laquelle il n'existe actuellement pas de référence bibliographique sur ce sujet. 


\section{Matériel et Méthodes}

Deux méthodes de mesure de l'ANR ont été utilisées: - la méthode in vivo (Jaworski, 1971; Radin, 1973; Nicholas et al., 1976; Jones et Sheard, 1977; Perez et Kliewer, 1978) testée en 1983 sur le domaine de SaintPaul à Montfavet;

- la méthode in situ (Robin et al., 1983) expérimentée en 1987 sur le domaine de Gotheron à Saint-Marcellès-Valence.

\section{Matériel}

L'expérimentation sur la méthode de mesure in vivo de l'activité NR est réalisée sur des scions (jeunes arbres greffés) âgés d'un an de pêchers cultivar «Suncrest/GF655-2". Ceux-ci sont cultivés sous serre et en hydroponie dans des pots individuels de 6 litres. La solution est composée des éléments suivants: $\mathrm{Ca}\left(\mathrm{NO}_{3}\right)_{2} 5 \mathrm{mM}, \mathrm{CaCl}{ }_{2} 1 \mathrm{mM}, \mathrm{K}_{2} \mathrm{SO}_{4} 1 \mathrm{mM}, \mathrm{MgSO}_{4}$ $1,5 \mathrm{mM}, \mathrm{NaH}_{2} \mathrm{PO}_{4} 1 \mathrm{mM}$, citrate de fer $100 \mu \mathrm{M}, \mathrm{H}_{3} \mathrm{BO}_{3}$ $30 \mu \mathrm{M}, \mathrm{MnCl}_{2} 10 \mu \mathrm{M}, \mathrm{CuSO}_{4} 1 \mu \mathrm{M}, \mathrm{ZnSO}_{4} 1 \mu \mathrm{M}$ et

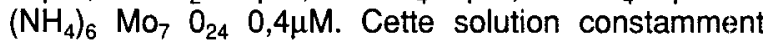
aérée est renouvelée tous les 7 à 14 jours. L'alternance des températures est de 25 à $15^{\circ} \mathrm{C}$ entre le jour et la nuit, l'humidité relative varie de 70 à $80 \%$.

Pour la mesure dite in situ de l'activité NR, on prélève des feuilles sur des pêchers adultes cultivar "Suncrest/GF305" plantés sur un sol de type sablo-limoneux. Ces arbres reçoivent une fertilisation azotée (nitrate d'ammonium) de 120 unités apportées de façon fractionnée au cours de leur cycle végétatif. L'activité NR in situ est aussi mesurée dans les racines de jeunes pêchers d'un an (lignée pure GF305), ayant poussé sur sol sableux. Après arrachage des arbres et rinçage des racines, chaque pêcher est transporté au laboratoire et maintenu dans un litre de solution nutritive aérée et sans azote, contenant les éléments suivants: $\mathrm{KH}_{2} \mathrm{PO}_{4} 1 \mathrm{mM}, \mathrm{CaCl}_{2} 0,5 \mathrm{mM}, \mathrm{MgSO}_{4} 0,5 \mathrm{mM}$, citrate de fer $20 \mu \mathrm{M}, \mathrm{MnSO}_{4} 1 \mu \mathrm{M}, \mathrm{CuSO}_{4} 0,1 \mu \mathrm{M}$, $\mathrm{H}_{3} \mathrm{BO}_{3} 6 \mu \mathrm{M}$ et $\left(\mathrm{NH}_{4}\right)_{6} \mathrm{Mo}_{7} \mathrm{O}_{24} 0,2 \mu \mathrm{M}$.

\section{Méthodes}

Les prises d'échantillon pour les mesures d'activité nitrate réductase et de teneur en nitrate des tissus s'effectuent de la façon suivante:

- sur les pêchers adultes, on prélève une feuille située sur une pousse végétative en croissance (Bres et al., 1970). Cette pousse, longue de 20 à $30 \mathrm{~cm}$ et composé de 15 à 20 feuilles, est choisie sur la partie extérieure de l'arbre, toujours orientée à l'est et à une hauteur de $1,50 \mathrm{~m}$ à $2 \mathrm{~m}$ du sol;

- sur les jeunes pêchers, on choisit si possible des feuilles de même âge, même taille et situées au même niveau sur le rameau. Quant aux racines, seules les non lignifiées d'un diamètre voisin de $1 \mathrm{~mm}$ sont utilisées après avoir été rincées à l'eau distillée.

Les protocoles de mesure de l'activité nitrate réductase ont fait l'objet d'une mise au point méthodologique (voir plus bas). Le nitrate est dosé à l'aide d'une chaîne automatique comportant une colonne réductrice de cadmium (Treguer et Lecorre, 1975). Les résultats d'activité nitrate réductase sont exprimés en micromole de nitrite formé par heure et par gramme de matière fraîche ( $\mu \mathrm{mol} . \mathrm{NO}_{2}-h^{-1} \cdot g^{-1}$ M.F.) et les résultats de teneur en nitrate des tissus en micromole de nitrate par gramme de matière fraîche ( $\mu$ mol. $\mathrm{NO}_{3}-\mathrm{g}^{-1}$ M.F.). Les valeurs obtenues sont la moyenne de 5 à 12 répétitions.

Une induction préalable de l'activité nitrate réductase (voir p. 413) peut être réalisée selon les méthodes suivantes:

- en prélevant sur des pêchers adultes des pousses végétatives comportant environ 15 feuilles. L'extrémité excisée de la pousse est plongée, soit dans une solution à $20 \mathrm{mM}$ de $\mathrm{KNO}_{3}$ pour des durées comprises entre 0 et $8 \mathrm{~h}$, soit pendant $6 \mathrm{~h}$ dans des solutions de concentrations en $\mathrm{KNO}_{3}$ comprises entre 0 et $100 \mathrm{mM}$; - en transférant de jeunes pêchers sur des solutions contenant du nitrate, soit à une concentration de 50 $\mathrm{mM}$ et pour des durées comprises entre 0 et $48 \mathrm{~h}$, soit à des concentrations variant de 0 à $100 \mathrm{mM}$ pendant $8 \mathrm{~h}$ pour les feuilles et $30 \mathrm{~h}$ pour les racines. Les mesures de I'ANR sont réalisées sur feuilles et racines des mêmes arbres qui reçoivent pendant la durée de l'induction un éclairement de $38 \mathrm{~W} \cdot \mathrm{m}^{-2}$.

\section{Résultats et discussion}

Mise au point de la méthode de mesure de l'activité nitrate réductase

Chez le pêcher, des inhibiteurs endogènes inactivent l'enzyme nitrate réductase lors de la mise en œuvre d'un protocole de mesure in vitro de l'ANR (Reilly et al., 1986), ce qui nous a conduits à utiliser d'autres méthodes de mesure de l'ANR. Deux techniques ont été comparées: soit la méthode dite in vivo, où l'incubation des échantillons végétaux a lieu dans des solutions de $\mathrm{KNO}_{3}$ à différentes concentrations, soit la méthode in situ où l'incubation a lieu en milieu gazeux sous atmosphère d'azote, le substrat $\mathrm{NO}_{3}$ étant fourni à la nitrate réductase en plongeant le pétiole de la feuille excisée dans une solution de $\mathrm{KNO}_{3}$. Dans le cas où la mesure est faite sur des racines, celles-ci sont plongées dans la solution de $\mathrm{KNO}_{3}$.

\section{1) Mesure in vivo, définition des conditions de mesure}

De 0,3 à 0,4 gramme de tissus frais sont plongés dans $4,8 \mathrm{ml}$ d'une solution d'incubation contenant du $\mathrm{KNO}_{3}$ et un tampon phosphopotassique $(\mathrm{pH}$ 7,5 ). L'incubation est réalisée dans des tubes étanches soumis à une infiltration sous vide partiel (à $65 \mathrm{~cm}$ de mercure pendant $2 \mathrm{~min}$ ), puis maintenus à l'obscurité pendant toute la durée de l'incubation. L'introduction d'un perméabilisant, le I-propanol à $1 \%(v / v)$, n'augmente pas l'activité NR foliaire. Ces activités, obtenues lors d'une expérimentation, sont respectivement de 0,535 et de $0,537 \mu \mathrm{mol} . \mathrm{NO}_{2}-\mathrm{h}^{-1} \cdot \mathrm{g}^{-1} \mathrm{MF}$ en absence ou en présence de propanol. Dans les racines ces mêmes valeurs sont de 0,392 et de 0,467 $\mu$ mol.h-1 $\cdot g^{-1}$ M.F. Cette faible différence étant 
été maintenue pour les mesures d'ANR des racines. Au niveau des feuilles, l'activité NR diminue pour des durées d'incubation comprises entre $15 \mathrm{mn}$ et $90 \mathrm{~min}$ et augmente avec la température jusqu'à $40^{\circ} \mathrm{C}$ (Tableau I), au-delà l'activité diminue rapidement (résultats non présentés). En outre, cette activité semble optimale pour des solutions d'incubation à $50 \mathrm{mM}$ de $\mathrm{KNO}_{3}$ (Fig. 2A). L'incubation in vivo des tissus de pêchers sera donc réalisée pendant $15 \mathrm{~min}$, en présence de $\mathrm{KNO}_{3}$ à $50 \mathrm{mM}$ et à la température de $40^{\circ} \mathrm{C}$. A la fin de la période d'incubation, les réactions enzymatiques sont arrêtées par addition de 0,2 $\mathrm{ml}$ de $\mathrm{KCN}(1 \mathrm{M})$. L'extraction du nitrite formé est faite, soit en broyant les tissus dans la solution d'incubation, soit en portant celle-ci à ébullition (Fig. 1). La corrélation entre les deux méthodes étant excellente $(r=0,99)$, la technique de l'ébullition sera retenue en raison de la simplicité de la mise en œuvre. Le nitrite est ensuite révélé par réaction de diazotation $(2 \mathrm{ml}$ de sulfanilamide et $2 \mathrm{ml}$ de NNEDD).

\section{2) Méthode in situ, définition des conditions de mesure}

Des feuilles ou des racines excisées sont placées dans un tube de $20 \mathrm{ml}$ fermé hermétique-

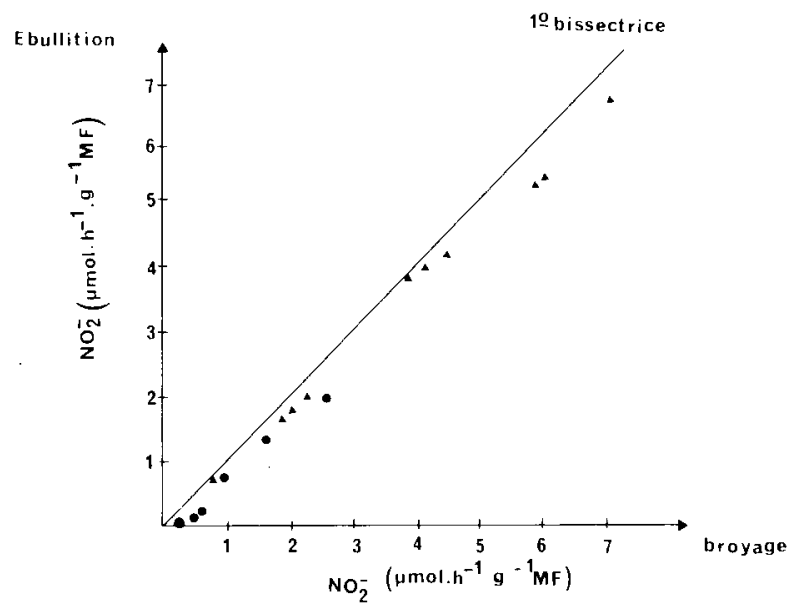

Fig. 1. ANR in vivo foliaire $(\bullet)$ et racinaire $(\Delta)$ de jeunes pêchers. Incubation pendant $15 \mathrm{~min}$ en présence de $\mathrm{KNO}_{3}$ à $50 \mathrm{mM}$. Extraction du nitrite soit par broyage, soit par ébullition du milieu d'incubation contenant les tissus végétaux. ment et un balayage d'azote de 1 min assure l'anoxie. Les tubes sont maintenus à l'obscurité et à température ambiante pendant la durée d'incubation. Pour les feuilles, l'accumulation du nitrite s'accroît avec le temps jusqu'à une valeur maximale atteinte au bout d'1 h (Fig. 2B), d'autres expériences ont indiqué que la quantité de nitrite produit n'était linéaire en fonction du temps que pour des durées d'incubation inférieures à $20 \mathrm{~min}$, nous retiendrons donc la durée d'incubation de 20 min pour nos mesures d'ANR in situ. Par ailleurs, l'activité NR foliaire apparaît optimale pour une concentration en $\mathrm{KNO}_{3}$ de 100 $\mathrm{mM}$ du milieu dans lequel plonge le pétiole (Fig. 2A), $2 \mathrm{ml}$ de cette solution d'incubation seront donc utilisés au cours de nos expérimentations. A la fin de la période d'incubation, les réactions enzymatiques sont arrêtées par addition d"eau bouillante dans le tube, qui est par la suite maintenu durant 10 min dans un bain-marie bouillant afin d'extraire le nitrite accumulé dans les tissus. Deux $\mathrm{ml}$ de sulfamide et $2 \mathrm{ml}$ de NNEDD sont, à la sortie du bain-marie, ajoutés dans le tube pour le dosage colorimétrique du nitrite.

La similitude des résultats obtenus par les méthodes de mesure in vivo et in situ nous a conduit à ne retenir que la deuxième pour les expériences. En effet, la méthode in situ est la plus simple à mettre en œuvre.

\section{Variations de I'ANR foliaire mesurée in situ}

L'activité nitrate réductase mesurée in situ décroît des feuilles récentes aux feuilles les plus anciennes de la pousse végétale (Fig. $3 \mathrm{~A}$ ). Toutefois, les feuilles proches de l'apex, c'est-à-dire en cours de formation, ont une ANR inférieure à l'ANR maximale. La réduction du nitrate semble ainsi essentiellement localisée au niveau de feuilles jeunes, mais complètement développées, ce qui est en accord avec les observations de Scheller (1984) sur la vigne.

L'ANR folaire in situ maximale est mesurée en milieu de journée (Fig. 3B). Les valeurs obte-

Tableau I. Influence de conditions d'incubation sur l'ANR foliaire mesurée in vivo de jeunes pêchers. Incubation en présence de $\mathrm{KNO}_{3}$ à $50 \mathrm{mM}$, d'une part pendant des durées variant de 15 à 90 min et à une température constante de $30^{\circ} \mathrm{C}$, d'autre part à des températures comprises entre 15 et $40^{\circ} \mathrm{C}$ et pour une durée de $15 \mathrm{~min}$. Les deux expériences ont été réalisées au cours de journées climatiquement très différentes. (a) $\mu \mathrm{mol} \cdot \mathrm{NO}_{2}-\mathrm{h}^{-1} \cdot \mathrm{g}^{-1} \mathrm{M}$.F.

Durée de l'incubation (min.)

Température $\left({ }^{\circ} \mathrm{C}\right)$

$\begin{array}{llllllllll}15 & 30 & 45 & 60 & 90 & 15 & 20 & 25 & 30 & 40\end{array}$

\begin{tabular}{lllllllllll}
\hline ANR (a) & 0,41 & 0,22 & 0,23 & 0,21 & 0,12 & 0,63 & 0,65 & 0,79 & 0,94 & 1,2 \\
\hline
\end{tabular}



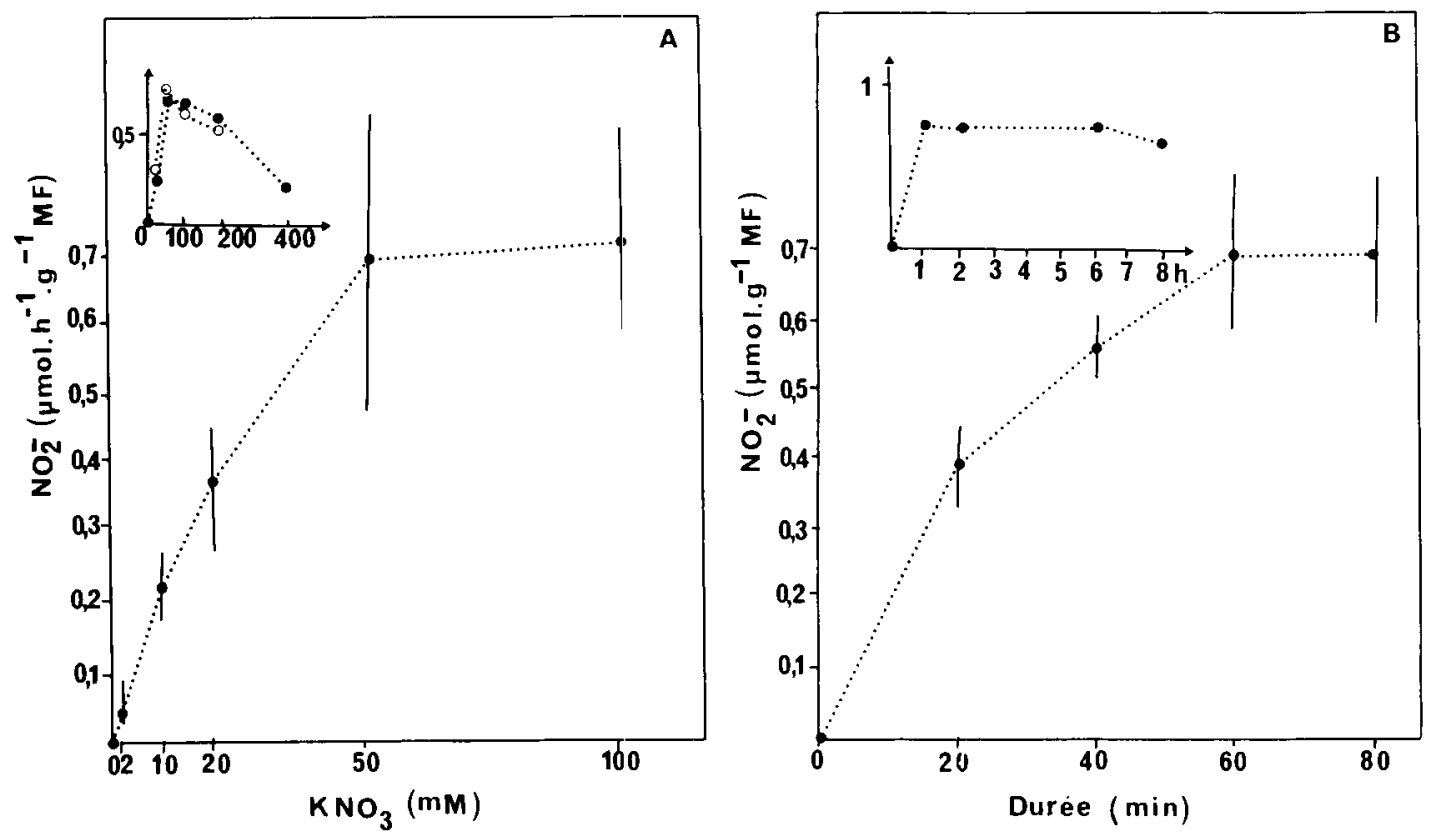

Fig. 2. Réduction foliaire du nitrate chez le pêcher selon:

A - la concentration en nitrate du milieu d'incubation. Durée d'incubation: 20 min pour la mesure in situ (@) et 15 min pour la mesure in vivo (O). Encart: réduction foliaire du nitrate pour une concentration en $\mathrm{KNO}_{3}$ du milieu d'incubation de 0 à $400 \mathrm{mM}$;

$\mathrm{B}$ - la durée d'incubation. La mesure in situ est réalisée en présence de $2 \mathrm{ml}$ de $\mathrm{KNO}_{3} 100 \mathrm{mM}$ dans le milieu. Encart: réduction foliaire du nitrate pour une durée d'incubation de 0 à $8 \mathrm{~h}$.

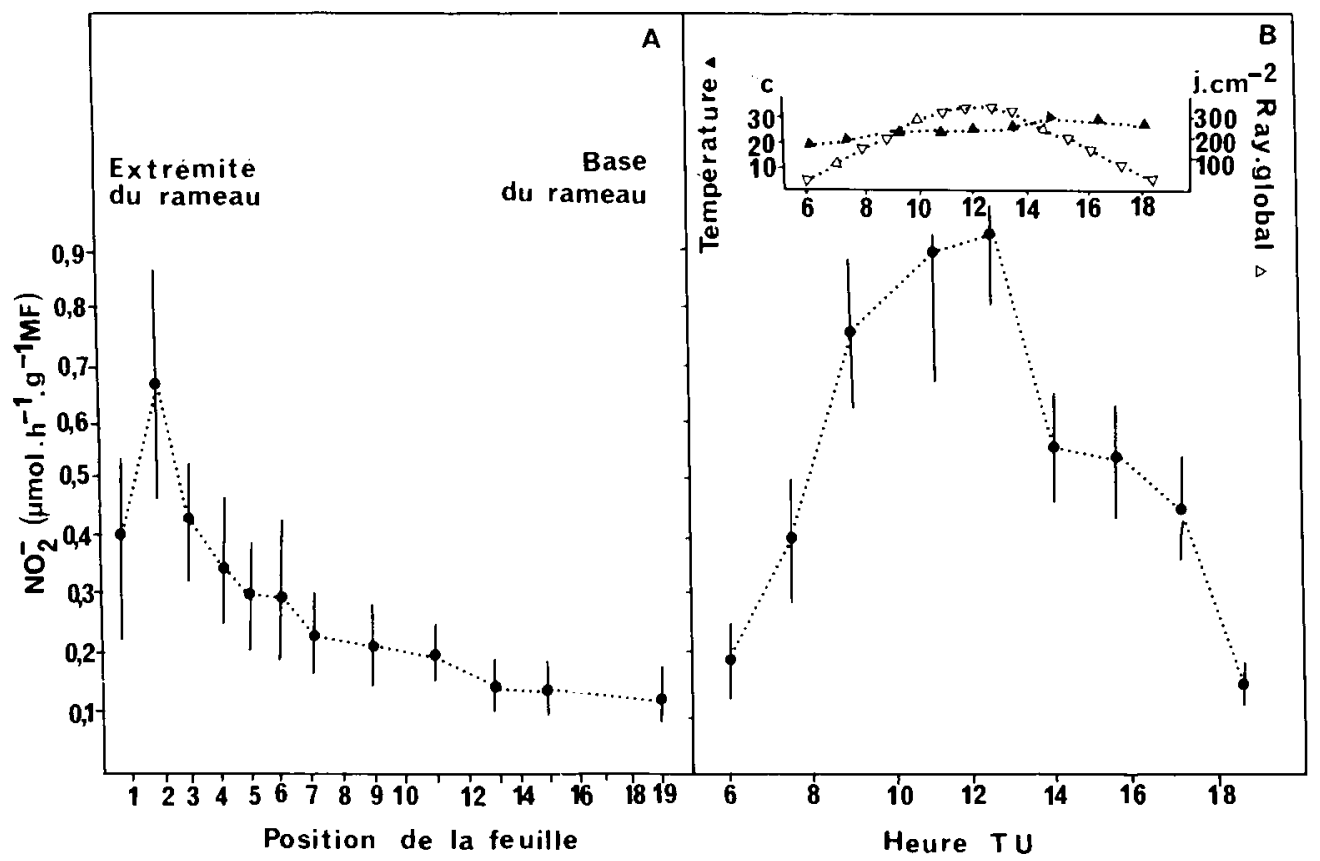

Fig. 3. Variation de l'ANR foliaire in situ de pêchers adultes selon:

A - la position de la feuille sur la pousse végétative. Mesure de l'ANR à $12 \mathrm{HTU}$ en présence de $2 \mathrm{ml}$ de $\mathrm{KNO}_{3}$ à $100 \mathrm{mM}$ dans le milieu d'incubation.

B - l'heure de la journée. Mesure de l'ANR de feuilles situées à proximité de l'apex sur la pousse végétative. Encart: variations de la température et du rayonnement global au cours de la jourriée.

nues entre 10 et $12 \mathrm{~h}$ en temps universel (HTU) sont 4 à 5 fois plus élevées que les valeurs minimales observées à $6 \mathrm{~h}$ et $18 \mathrm{~h}$. Nous pouvons formuler l'hypothèse que cette évolution serait liée soit à une intensité d'éclairement plus élevée, soit à une température ambiante plus favorable. Cependant, au cours de l'expérimentation présentée, l'ANR décroît de $12 \mathrm{~h}$ à $18 \mathrm{~h}$, bien que la température augmente légèrement dans le même temps. La diminution de l'intensité de l'éclairement représenterait donc dans ce cas un facteur limitant de l'ANR.

\section{Induction de l'activité nitrate réductase}

\section{1) ANR foliaire}

L'ANR est induite au cours du séjour de pousses végétatives d'arbres adultes dans des solutions 
contenant du nitrate. Elle atteint une valeur optimale après $6 \mathrm{~h}$ d'induction (Tableau II) et pour une concentration en nitrate du milieu de $50 \mathrm{mM}$ (Fig. 4A). Au-delà, l'accumulation de nitrate (Fig. 4B) entraîne une inhibition de l'ANR, ce qui signifie vraisemblablement que la fraction métabolisable située dans le cytoplasme correspond à des concentrations qui deviennent inhibitrices de l'activité de l'enzyme (Robin et al., 1983). L'ANR maximale obtenue est voisine de 2 $\mu$ mol. $\mathrm{NO}_{2}-\mathrm{h}^{-1} \cdot \mathrm{g}^{-1} \mathrm{MF}$. Ce résultat est comparable aux ANR maximales obtenues par Klepper et Hageman (1969) sur pommier (1,3 $\mu \mathrm{mol} . \mathrm{NO}_{2}-\mathrm{h}^{-1} \cdot \mathrm{g}^{-1} \mathrm{M} . \mathrm{F}$.) et par Leece et al. (1972) sur abricotier (2,2 $\mu$ mol. $\mathrm{NO}_{2}-\mathrm{h}^{-1} \cdot \mathrm{g}^{-1}$ M.F.). Cependant, ces auteurs utilisaient une méthode de mesure in vitro qui théoriquement donne des valeurs d'ANR proportionnelles à la quantité d'enzyme. Autrement dit, ou la nitrate réductase fonctionne in situ à sa vitesse maximale, ou I'ANR mesurée in vitro sur les feuilles de rosacées fruitières est sous-estimée à cause de facteurs d'inactivation qui n'ont pas été maîtrisés au cours de l'extraction.

En l'absence de nitrate exogène, provenant soit du milieu d'incubation soit du milieu d'induction, l'ANR foliaire in situ est nulle (Fig. 4A). Ceci pourrait signifier que le flux de nitrate parvenant spontanément, en condition de culture, au niveau des feuilles est insuffisant pour induire une activité nitrate réductase.

\section{2) Comparaison ANR racinaire et ANR foliaire}

L'ANR mesurée in situ apparaît maximale après un temps d'induction de $30 \mathrm{~h}$ pour les racines et de $8 \mathrm{~h}$ pour les feuilles (Tableau II). Pour ces mêmes durées et pour des concentrations croissantes en nitrate du milieu d'induction, l'ANR au niveau des racines augmente de 0,1 à 0,6 $\mu$ mol. $\mathrm{NO}_{2}-\mathrm{h}^{-1} \cdot \mathrm{g}^{-1} \mathrm{MF}$ et l'ANR foliaire de 0 à 0,3 $\mu \mathrm{mol} . \mathrm{NO}_{2}-\mathrm{h}^{-1} \cdot \mathrm{g}^{-1} \mathrm{MF}$ (Fig. 5). Dans nos conditions expérimentales, l'activité nitrate réductase des racines apparaît donc inductible par son substrat et supérieure à l'activité des feuilles, cet

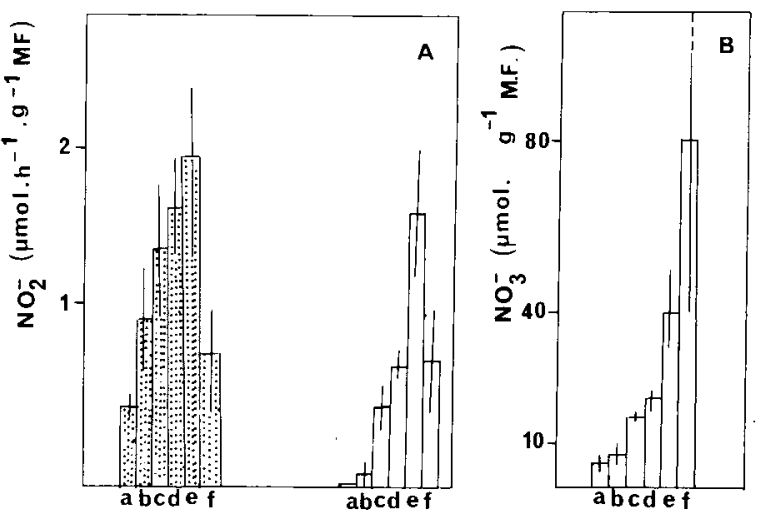

Fig. 4. Réduction foliaire du nitrate chez des pêchers adultes selon la concentration en nitrate du milieu d'induction (a) $\mathrm{OmM}$, (b) $5 \mathrm{mM}$, (c) $10 \mathrm{mM}$, (d) $20 \mathrm{mM}$ ), (e) $50 \mathrm{mM}$, (f) $100 \mathrm{mM}$. Durée de l'incubation: $6 \mathrm{~h}$

A - ANR foliaire in situ; incubation en présence de $2 \mathrm{ml}$ de $\mathrm{KNO}_{3}$ à $100 \mathrm{mM}\left[::: \mathrm{:}\right.$, sans $\mathrm{NO}_{3}$ exogène $\square$; $B$ - teneur en nitrate des feuilles.

écart étant accentué si les ANR sont exprimées en poids de matière sèche $(M S / M F \simeq 10 \%$ pour les racines, $20 \%$ pour les feuilles). Nos conclusions ne concordent pas avec celles de Klepper et Hageman (1969) qui observent, pour des jeunes plants de pommier, une ANR foliaire plus importante que l'ANR racinaire. Cependant, le milieu nutritif utilisé par ces auteurs comprend de l'ammonium (environ $25 \%$ de l'azote) et pour de telles conditions, comme le souligne Frith (1972), l'acitivité nitrate réductase des racines peut être notoirement diminée sans que celle des feuilles ne soit toutefois affectée.

\section{Conclusion}

La méthode de mesure in situ utilisée au cours de ce travail apparaît opérationnelle et permet d'avoir une appréciation des activités de réduction du nitrate par des feuilles et des racines de pêchers et d'établir par conséquent des comparaisons entre traitements. Cette mesure donne des indications sur l'assimilation du $\mathrm{NO}_{3}-$ par les rosacées fruitières. Depuis très longtemps, il a

Tableau II. Influence de la durée de l'induction sur l'ANR in situ de pêchers jeunes et adultes. Durée d'incubation: 20 min, la partie excisée des organes plongeant dans $2 \mathrm{ml}$ d'une solution de $\mathrm{KNO}_{3}$ à $100 \mathrm{mM}$. (a) $\mu \mathrm{mol} \cdot \mathrm{NO}_{2}-\mathrm{h}^{-1} \cdot \mathrm{g}^{-1} \mathrm{M} \cdot \mathrm{F}$; (b) Intervalle de confiance au seuil de $5 \%$.

Durée de l'induction (heures)

\begin{tabular}{|c|c|c|c|c|c|c|c|c|c|c|}
\hline & & 0 & 1 & 2 & 4 & 6 & 8 & 24 & 30 & 48 \\
\hline $\begin{array}{l}\text { Arbres adultes } \\
\text { Jeunes arbres }\end{array}$ & $\begin{array}{l}\text { ANR (a) } \\
\text { foliaire (b) } \\
\text { ANR (a) } \\
\text { foliaire (b) } \\
\text { ANR (a) } \\
\text { racinaire (b) }\end{array}$ & $\begin{aligned} & 0,16 \\
& \pm 0,04 \\
& 0 \\
& 0,11 \\
& \pm 0,03\end{aligned}$ & $\begin{array}{c}0,32 \\
\pm 0,1 \\
- \\
-\end{array}$ & $\begin{array}{r}0,36 \\
\pm 0,09 \\
- \\
-\end{array}$ & $\begin{array}{c}0,49 \\
\pm 0,2 \\
- \\
-\end{array}$ & $\begin{array}{r}0,66 \\
\pm 0,25 \\
- \\
-\end{array}$ & $\begin{array}{r}0,60 \\
\pm 0,25 \\
0,31 \\
\pm 0,08 \\
0,15 \\
+0,04\end{array}$ & $\begin{array}{r}- \\
0,19 \\
\pm 0,08 \\
0,15 \\
\pm 0,03\end{array}$ & $\begin{array}{r}- \\
0,26 \\
\pm 0,10 \\
0,40 \\
\pm 0,05\end{array}$ & $\begin{array}{r}- \\
0,12 \\
\pm 0,08 \\
0,17 \\
\pm 0,07\end{array}$ \\
\hline
\end{tabular}




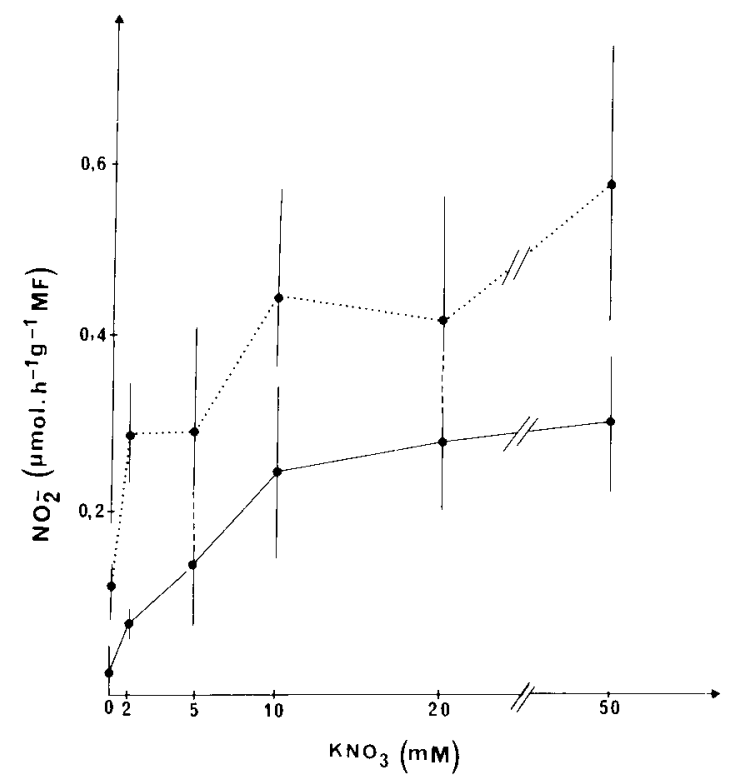

Fig. 5. ANR in situ de feuilles (- $\longrightarrow$ et de racines (... ....... de jeunes pêchers selon la concentration en nitrate du milieu d'induction. Durée de l'induction: $30 \mathrm{~h}$. Incubation en présence de $2 \mathrm{ml}$ de $\mathrm{KNO}_{3}$ à $100 \mathrm{mM}$.

été avancé que la réduction du nitrate chez ces végétaux se faisait exclusivement dans les racines. Les observations rapportées ci-dessus confirment celles d'autres auteurs qui ont clairement mis en évidence une ANR foliaire. Chez les arbres fruitiers, la part respective des racines et des feuilles dans la réduction du nitrate n'est donc pas encore totalement élucidée.

Or la localisation de l'assimilation du nitrate joue un rôle essentiel dans la physiologie de la plante. Ainsi, chez la plupart des végétaux supérieurs de type herbacé, la réduction du nitrate s'effectue essentiellement dans les feuilles. Cette réaction qui produit l'ammonium utilisé dans la biosynthèse des acides aminés, s'accompagne de la formation d'un groupement hydroxyle dont l'élimination est indispensable afin de maintenir le $\mathrm{pH}$ cellulaire. La synthèse d'un groupement carboxyle - $\mathrm{COOH}$ par carboxylation du phosphoénol pyruvate fournit le proton nécessaire à cette élimination de l'ion $\mathrm{OH}^{-}$avec formation d'une molécule d'eau, le groupement anionique $-\mathrm{COO}$ - assure simultanément la neutralisation de la charge cationique qui est entrée dans la cellule avec le nitrate. Les acides organiques ainsi formés (malate, citrate, oxalate ...) et les ions nitrates non réduits s'accumulent dans la vacuole avec les cations, participant ainsi à l'établissement du potentiel osmotique indispensable au maintien de la turgescence des tissus. Ainsi la réduction du $\mathrm{NO}_{3}$ - est un processus physiologique étroitement associé au métabolisme carboné et hydrique de la plante et constitue de ce fait un aspect important de l'adaptation de ces végétaux à leur environnement (Salsac et al., 1987). Une étude approfondie de ce mécanisme chez les rosacées fruitières apparaît donc nécessaire dans l'objectif d'une meilleure compréhension de leur comportement.

\section{Références}

Bollard E.G. (1957) Composition of the nitrogen fraction of apple tracheal sap. Aus. J. Biol. Sci. 10, 279287

Bres Y., Golinsky P., Nigond J., Tabard P., Guichard L., Boulon P. \& Rose J. (1970) Recherches sur le développement du pêcher. Phytoma Def. Cult. 219, 1-8

Frith G.J.T. (1972) Effect of ammonium nutrition on the activity of nitrate reductase in roots of apple seedlings. Plant Cell Physiol. 13, 1085-1090

Habib R. (1984) La formation des réserves azotées chez les arbres fruitiers. Revue bibliographique. Fruits (Paris) 39, 623-635

Jaworski E.G. (1971) Nitrate reductase assay in intact plant tissues. Biochem. Biophys. Res. Commun. 43, 1274-1279

Jones R.W. \& Sheard R.W. (1977) Conditions affecting in vivo nitrate reductase activity in chlorophyllous tissues. Can. J. Bot. 55, 896-901

Klepper L. \& Hageman R.H. (1969) The occurence of nitrate reductase in apple leaves. Plant Physiol. 44, 110-114

Leece D.R., Dilley D.R. \& Kenworthy A.L. (1972) The occurence of nitrate reductase in leaves of Prunus species. Plant Physiol. 49, 725-728

Nicholas J.C., Harper J.E. \& Hageman R.H. (1976) Nitrate reductase activity in soybeans (glycine $\max (\mathrm{L}$.) Merr.). Plant Physiol. 58, 731-735

Pate J.S. (1973) Uptake, assimilation and transport of nitrogen compounds by plants. Soil. Biol. Biochem. 5, 109-119

Perez J.R. \& Kliewer W.N. (1978) Nitrate reduction in leaves of grapevine and other fruit trees. J. Am. Soc Hortic Sci. 103, 246-250

Radin J.W. (1973) In vivo assay of nitrate reductase in cotton leaf discs. Plant Physiol. 51, 332-336

Reilly C.C., Edwards J.H. \& Okie W.R. (1986) Isolation and characterization of endogenous inhibitors of nitrate reductase of peach (Prunus persica (L.) Batsch) and their distribution in the genus Prunus. J. Plant Nutr. 9, 1335-1351

Robin P., Conegero G., Passama L. \& Salsac L. (1983) Evolution de la fraction métabolisable du nitrate par la mesure in situ de sa réduction. Physiol. Vég. 21, 123-128

Salsac L., Chaillou S., Morot-Gaudry J.F., Lesaint C. \& Jolivet E. (1987) Nitrate and ammonium nutrition in plants. Plant Physiol. Biochem. 25, 805-812

Scheller K. (1984) Untersuchungen zur Nitratereduktase. Aktivität in Reben. Mitt. Klosterneuburg 34, 235240

Taylor B.K. \& Van Den Ende B. (1969) The nitrogen nutrition of the peach tree. IV: Storage and mobilization of nitrogen in mature tress. Aust. J. Agric. Res. 20, 869-881

Treguer P. \& Lecorre P. (1975) Manuel d'Analyse des Sels Nutritifs dans l'Eau de Mer. Université de Bretagne occidentale, Brest, pp. 11-22 